CASE REPORT

\title{
Bilateral leg ulcers secondary to dystrophic calcinosis in a patient with rheumatoid arthritis
}

\author{
Tetsuya Hida ${ }^{1,2}$, Mitsuyoshi Minami ${ }^{1}$, and Yoshiaki Kubo² \\ ${ }^{1}$ Division of Dermatology, Matsuyama Red Cross Hospital, Matsuyama, and ${ }^{2}$ Department of Dermatology, Tokushima University Graduate \\ School of Medical Science, Tokushima, Japan
}

\begin{abstract}
Calcinosis cutis can be classified into four subtypes : dystrophic, metastatic, idiopathic, and iatrogenic. Of these subtypes, dystrophic calcinosis (DC) is the most common, and is most frequently associated with connective tissue disease, particularly dermatomyositis and systemic sclerosis, and less commonly with systemic lupus erythematosus. However, DC associated with rheumatoid arthritis (RA) is extremely rare. In this paper, we present a Japanese woman with RA, who suffered from bilateral leg ulcers secondary to DC. To the best of our knowledge, only two cases of DC associated with RA have been reported to date. Similar to this case, the DC lesions were observed in the extremities, including the buttocks in the other two cases. Although the ulcers on her left leg were gradually epithelialized after one year, they may easily recur due to whitish abnormal underlying tissues, and a large ulcer remains on her right leg. Thus, it is important for physicians to identify DC when encountering non-healing leg ulcers associated with connective tissue diseases. J. Med. Invest. 64 : 308-310, August, 2017
\end{abstract}

Keywords : bilateralleg ulcers, calcinosis cutis, dystrophic calcinosis, rheumatoid arthritis, connective tissue disease

\section{INTRODUCTION}

Calcinosis cutis is a rare disorder characterized by deposits of insoluble calcium salts in the skin and subcutaneous tissue, and can be classified into four subtypes : dystrophic, metastatic, idiopathic, and iatrogenic $(1,2)$. Of these subtypes, dystrophic calcinosis (DC) is the most common, and is most frequently associated with connective tissue disease (CTD), particularly dermatomyositis and systemic sclerosis, and less commonly with systemic lupus erythematosus $(1,2)$. However, DC associated with rheumatoid arthritis (RA) is extremely rare $(2,3)$. We present a Japanese woman with RA, who suffered from bilateral leg ulcers secondary to DC.

\section{CASE REPORT}

A 67-year-old Japanese woman was referred to our hospital with painful ulcers in her left leg for 8 months. She had been suffering from RA for 44 years, and was treated with $7 \mathrm{mg}$ /day oral prednisolone. Artificial joint replacements were performed in bilateral hip and knee joints, and no obvious arthritis was shown in other joints. She was not diagnosed as malignant RA. Clinical features showed several ulcers up to $5 \mathrm{~cm}$ in diameter, with yellow necrotic tissue in her left lower leg (Fig. 1). Laboratory findings showed a normal level of serum total calcium $(9.2 \mathrm{mg} / \mathrm{dl})$ and a slightly reduced level of serum total phosphorus $(1.9 \mathrm{mg} / \mathrm{dl})$. She was positive for rheumatoid factor $(182 \mathrm{IU} / \mathrm{ml})$, anti-CCP antibody $(1418.5 \mathrm{U} / \mathrm{ml})$, antinuclear antibody (640 titer, speckled pattern), anti-U1-RNP antibody (over $240 \mathrm{U} / \mathrm{ml}$ ), anti-Sm antibody (10.2 U/ml), and anti-

Received for publication May 17, 2017 ; accepted June 22, 2017.

Address correspondence and reprint requests to Yoshiaki Kubo, Department of Dermatology, Tokushima University Graduate School of Medical Science, Kuramoto-cho, Tokushima, 770-8503, Japan and Fax : +81886-32-0434
SSA antibody (43.5 U/ml), but negative for anti-dsDNA antibody and anti-SSB antibody. No obvious clinical symptoms of other CTD, that meet diagnostic criteria for overlap syndrome, were observed. X-ray (Fig. 2) and computed tomography (Fig. 3) images of the legs revealed numerous calcifications in the subcutaneous tissue, and a white hard mass in an ulcer was shown to be calcification histologically (Fig. 4). We diagnosed this case as DC associated with RA. Neither impaired blood flow nor vascular calcification of her legs was observed by ankle-brachial indices, which were 1.21 and 1.24 for the left and right legs, respectively. An ulcer appeared and expanded on her right leg (Fig. 5). The ulcers on her left leg were gradually reduced in size and epithelialized by local debridement, antibiotics, and Trafermin after one year (Fig. 6). The ulcer on her right leg remains large.

\section{DISCUSSION}

Although DC is most frequently associated with CTD, to the best of our knowledge, only two cases of DC associated with RA have been reported to date $(2,3)$. Because RA is a common disease affecting approximately $0.5-1.0 \%$ of the world's population (4), DC associated with RA is extremely rare. Similar to this case, the DC lesions were observed in the extremities, including the buttocks in the other two cases. DC results from local tissue damage or abnormalities, such as alterations in the collagenous, elastic, or subcutaneous fat tissues (1). Several auto-antibodies were detected in the present case, although overlap CTD was excluded. Though reasons of the incidence of DC in the extremities and the very rare incidence of DC in patients with RA remain unidentified, we suspect that the continuous and long-term presence of factors such as autoimmune reaction, chronic inflammation, and repeated trauma may have cooperatively promoted the development of DC in the present case.

Non-healing leg ulcers due to DC with CTD have rarely been reported (5). In the present case, a large ulcer remains on her right 


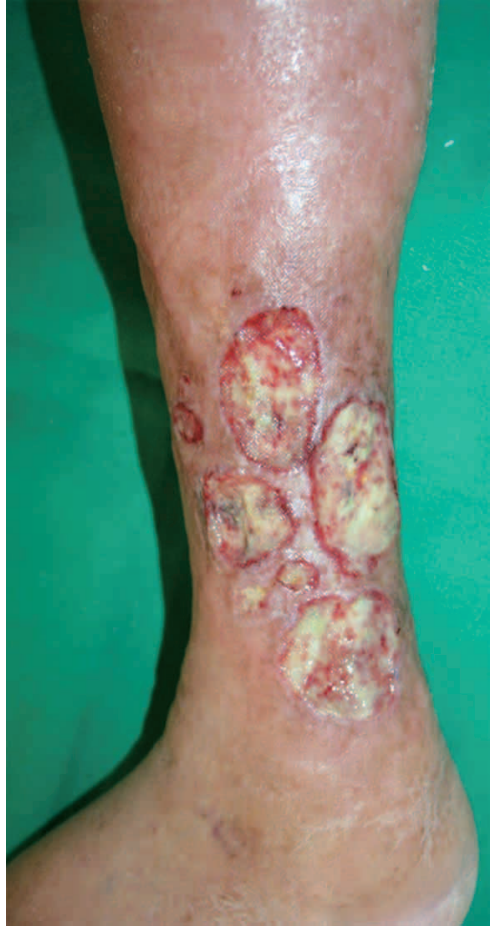

Fig. 1. Painful ulcers up to $5 \mathrm{~cm}$ in diameter on the left lower leg

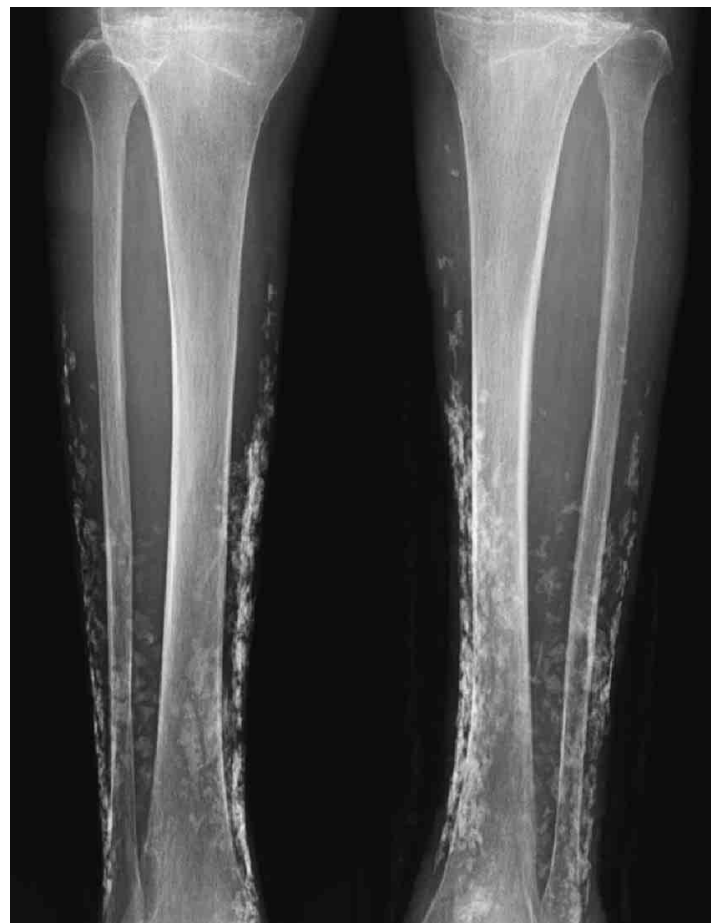

Fig. 2. X-ray images of both legs revealed numerous calcifications in the subcutaneous tissue.

leg, and the ulcers on her left leg may easily recur due to whitish abnormal underlying tissues. Thus, it is important for physicians to identify DC when encountering non-healing leg ulcers associated with CTD.

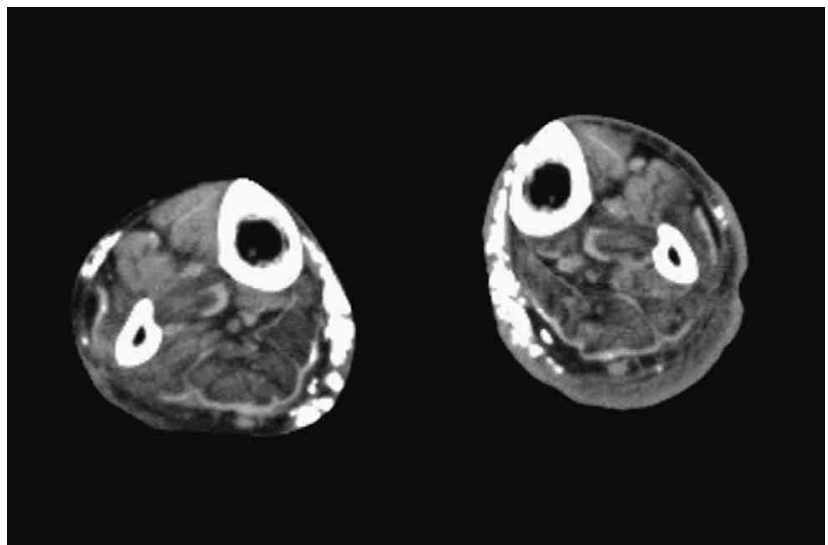

Fig. 3. Numerous calcifications in the subcutaneous tissue by computed tomography images of both legs

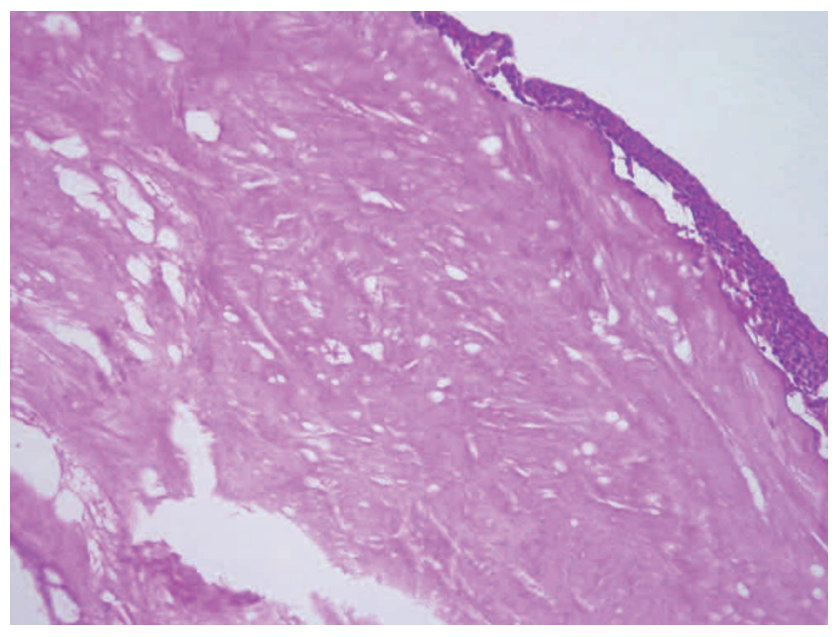

Fig. 4. Histopathological examination revealed that the white mass was calcification.

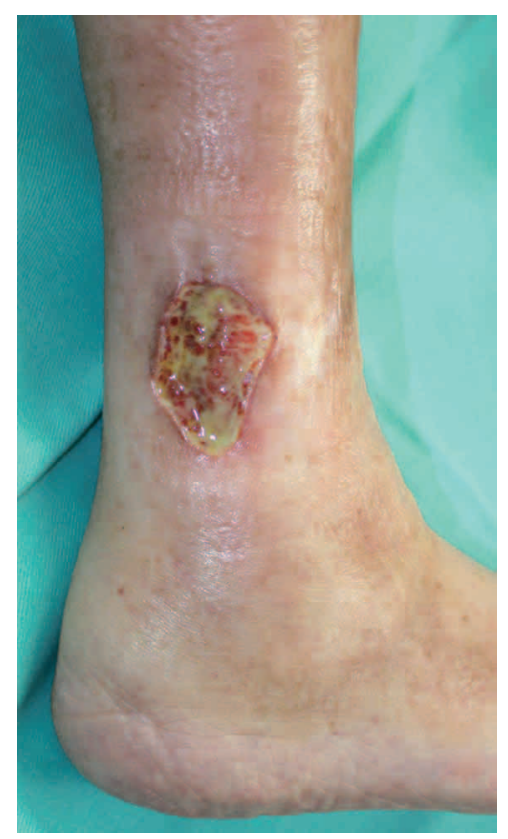

Fig.5. An ulcer on the right lower leg 


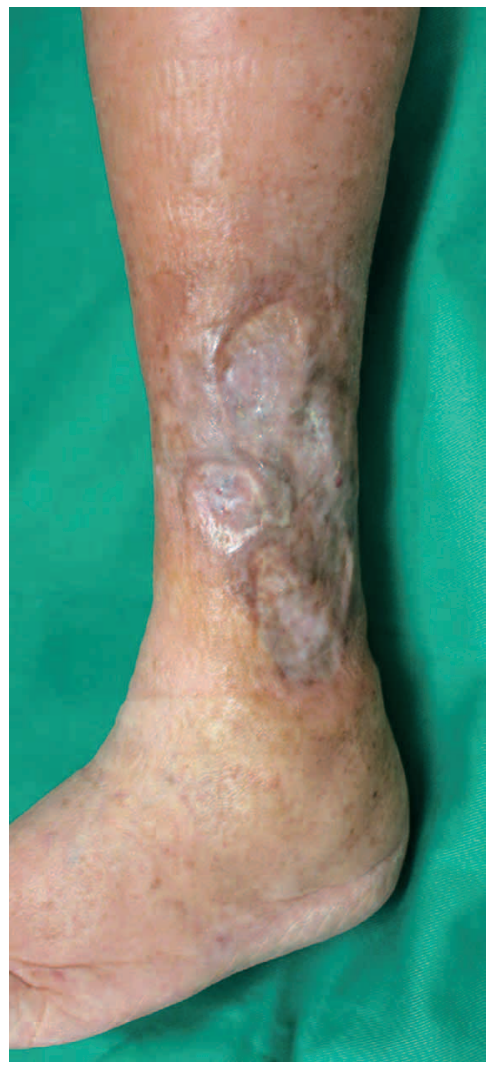

\section{CONFLICT OF INTEREST}

None declared.

\section{REFERENCES}

1. Reiter N, El-Shabrawi L, Leinweber B, Berghold A, Aberer E : Calcinosis cutis : part I. Diagnostic pathway. J Am Acad Dermatol $65: 1-12,2011$

2. Balin SJ, Wetter DA, Andersen LK, Davis MD : Calcinosis cutis occurring in association with autoimmune connective tissue disease : the Mayo Clinic experience with 78 patients, 1996-2009. Arch Dermatol 148 : 455-462, 2012

3. Harigane K, Mochida Y, Ishii K, Ono S, Mitsugi N, Saito T : Dystrophic calcinosis in a patient with rheumatoid arthritis. Modern Rheumatology $21: 85-88,2011$

4. Kochi Y, Suzuki A, Yamamoto K : Genetic basis of rheumatoid arthritis : a current review. Biochem Biophys Res Commun 452 : 254-262, 2014

5. Al-Najjar M, Jackson MJ : Non-healing leg ulcers in a patient with dystrophic calcification and crest syndrome : a challenging clinical case. Int Wound J 8 : 537-541, 2011

Fig. 6. Ulcers on the left leg were epithelialized, but whitish abnormal underlying tissues were observed. 